\title{
Melting Behavior of Phase Change Material in a Solar Vertical Thermal Energy Storage with Variable Length Fins added on the Heat Transfer Tube Surfaces
}

\author{
Ramalingam Senthil*, Aditya Patel, Rohan Rao, Sahil Ganeriwal
}

Department of Mechanical Engineering, SRM Institute of Science and Technology, Kattankulathur, Chennai, India

\begin{abstract}
This paper investigates the melting behaviour of phase change material (PCM) in a vertical thermal energy storage system with provision of thin rectangular fins of uniform and variable lengths on the heat transfer tube surfaces. The selected PCM and heat transfer fluid (HTF) are paraffin wax and water, respectively. The HTF is passed through the helically coiled copper tube of $10 \mathrm{~mm}$ diameter to melt the PCM. The time required to complete the melting of PCM in the system with fins is found to be five hours, whereas for the system without fins it is five hours and forty minutes, for the same conditions of constant water temperature of about $70^{\circ} \mathrm{C}$ and flow rate of $0.02 \mathrm{~kg} / \mathrm{s}$. HTF tube with fins is observed to be more effective with a $13.33 \%$ faster rate of melting when compared to that of the HTF tube without fins. Such a fast charging process will be helpful in storing maximum energy within a short period/duration of time shorter duration in for solar thermal and heat recovery applications during lean production times. O2020. CBIORE-IJRED. All rights reserved
\end{abstract}

Keywords: Thermal energy storage, solar energy, phase change materials, charging process, heat transfer fluid, energy storage capacity.

Article History: Received: 3 $3^{\text {rd }}$ April 2020; Revised: 15 ${ }^{\text {th }}$ June 2020; Accepted: 25 ${ }^{\text {th }}$ June 2020; Available online: $26^{\text {th }}$ June 2020

How to Cite This Article: Senthil, R. (2020) Melting Behavior of Phase Change Material in a Solar Vertical Thermal Energy Storage System with Variable Length Fins added on the Heat Transfer Tube Surfaces. International Journal of Renewable Energy Development, 9(3), 361-367. https://doi.org/10.14710/ijred.2020.29879

\section{Introduction}

Solar energy utilization is one of the fastest-growing and cost-competitive renewable energy resources worldwide. As solar energy is not a continuous energy source and is not available at night time, there is a mismatch between the energy supply and demand. The thermal requirements during the night and early morning necessitated the development of thermal energy storage (TES) for solar energy systems. TES is a type of energy system that uses the concept of both sensible and latent heat to store the captured heat energy from compact solar thermal collectors and waste heat recovery systems, without loss. TES provides the stored heat use fort at a later time for applications like heating and drying. Thermal energy can be stored either as sensible or latent heat. Latent heat storage (LHS) has a higher capacity to store energy per unit volume compared to sensible heat storage due to latent heat of phase change. PCM's have a low thermal conductivity between 0.1-0.7 W/m-K. The present review of literature focuses on the improvement of the thermal conductivity of PCMs using fins.

LHS depends upon the fast absorption and release of latent heat at the same temperature when a storage material goes through a change of phase from solid to liquid during the day and liquid to solid later when the heat is discharged to thermal applications. Phase change materials (PCMs) are used in LHS. The range of temperature for the transition of paraffin from solid to liquid phase is $50^{\circ} \mathrm{C}-110^{\circ} \mathrm{C}$ and the range of heat of fusion is found to vary between $180-210 \mathrm{~kJ} / \mathrm{kg}$. Paraffin wax is commercially available with different melting ranges and does not involve phase change segregation.

The enhancement of the heat transfer to and from the PCM using metallic fins on the heat transfer tube surfaces has been studied by several researchers over the past decades. The thermal performance of LHS was investigated with stainless-steel fins and aluminum fins of different thicknesses inside the tube to increase the heat transfer rate of the PCM (Wang et al. 2019). The use of wavy channels in the PCM was observed to result in a significant improvement of the charging and the discharging mechanism of PCM (Shahsavar et al. 2019). The thermal storage unit was studied by using a multichannel flat tube and rectangular fins; the convective heat transfer coefficient was observed to increase up to $515 \mathrm{~W} / \mathrm{m}^{2} \mathrm{~K}$ (Chen et al. 2019). The temperature distribution and energy storage in an annular PCM was enhanced by inclusion of fins in the longitudinal and traverse directions in a cylindrical thermal energy storage (Mostafavi et al. 2020).

The decreasing fin edge length ratio helped to significantly reduce the melting time, whereas, it had an

\footnotetext{
* Corresponding author: rsenthilsrm@gmail.com
} 
insignificant effect on the solidification time (Yagci et al. 2019). The addition of a conducting fin within the inner tube helped to intensify the recirculation process in the bottom half region of the space. The solidification time was reduced due to the novel corrugated configuration of fins, in comparison to the straight fin configuration even though the effectiveness of the corrugated fins was generally less than that of straight fins (Aly et al. 2019).

Heat transfer by natural convection was observed to occur in fins due to friction (Vogel et al. 2019). There appears to be a considerable impact of the natural convection occurring in fins, which are designed with a big tube spacing for low fin friction. Big fin heights lead to less heat transfer enhancement by natural convection. The horizontal design of the LHS was found to be effective compared to the vertical design for part-load operation due to the less time required to melt half of the mass of the PCM (Mehta et al. 2019). The added fins increased the rate of melting by $50 \%$; the melting rate was superior for the horizontal compared to the vertical orientation. However, for the finned tubes, minor variation was observed regarding the melting rate by changing the orientation (Mahdi et al. 2019). The inclined orientation of heat transfer fluid in the horizontal PCM storage was found to be capable of decreasing the melting duration (Senthil, 2019). Further, the effect of uniform and variable fin height in the horizontal PCM storage system was studied and the variable fin height was found more suitable to melt the PCM at the bottom of the energy storage (Senthil, 2019).

The effect of employing PCM in the annulus region and the inner tube was studied and the total solidification time of PCM for the annular region case was found to be lower by $43.4 \%$ compared to the inner tube (Mahdi et al. 2019). A conical shell and tube LHS system with fins, attached to the heat transfer fluid (HTF) tube was found to improve the thermal performance with a larger rate of heat transfer (Sodhi et al. 2019). Finned double tube configuration was found to be effective in enhancing the heat transfer to the PCM (Deng et al. 2019). In a horizontal PCM cylinder, the increase of the lateral surface of the cylinder improved the melting rate of the PCM. The natural convection played a major role in the top portion of the PCM and the solid PCM sank to the bottom due to gravity (Yadav et al. 2020). The non-melting region of the PCM in thermal energy storage was identified and the provision of special fins for that region was found to be effective in completely melting the PCM (Gürtürk and Kok, 2020). Employing PCM inside the tube was found to be more effective than the external PCM (Chen et al. 2020). The use of triangular geometries in solar air heaters was found to enhance the collector efficiency (Shukla et al. 2017). Productivity improvement of up to $17 \%$ was observed in a single-slope solar still with thermal energy storage (Bhalavi et al. 2019; Gupta et al. 2017).

The fin height was provided about three-fourth of the annulus radius and tested for the angle from 15 to 72 at the bottom of the horizontal LHS unit (Mahood et al., 2020). The bottom fin angle of 30 on the horizontal LHS was resulted in a reduction of melting time about by $16.7 \%$ due to improved convection due to the increased surfaces. The effect of fin orientation of angular fins in horizontal LHS unit using stearic acid as PCM was studied with Yfins and $\lambda$-type fins and Y-fins were observed to be effective in improving the melting rate of PCM that that of $\lambda$-fin arrangements (Khan and Khan, 2020). Melting behavior of lauric acid as PCM in a horizontal shell and finned heat storage unit was investigated to study the effect eccentric HTF tube and found that the heat storage rate of eccentric annulus is $18.7 \%$ higher than that of the concentric annulus (Kumar and Verma, 2020). The use of eccentric fins resulted in more uniformity in temperature distribution and observed with a $21 \%$ higher melting rate than that of the concentric case due to natural convection effects.

From the previous studies, it is evident that the use of differently shaped fins in the PCM is useful in increasing the rate of heat transfer. Most of the studies are focused on the horizontal LHS unit. Literature on the vertical LHS unit with different fin geometries has been observed a very limited. Simultaneous use of differently shaped fins on the HTF tube of TES systems has not been reported much in the literature. Hence, the effect of using uniform and variable length fins near the bottom of the vertical cylindrical thermal energy storage system is investigated in this work and the significant aspects of the observed results are reported here.

\section{Materials and Methods}

\subsection{Experimental work}

The experimental setup consists of a hot water supply tank and a reservoir to store the hot water. The water from the reservoir is pumped to the supply tank by using a hot water centrifugal pump. Three heating coils of $2 \mathrm{~kW}$ each are fixed on the hot water tank to heat the water to the required temperature of about $60-80^{\circ} \mathrm{C}$. Thus, this hot water source imitates real-time sources like solar thermal or waste heat recovery systems. Table 1 indicates the specifications of the TES experimental setup.

Thermostat control is used to maintain the temperature in the supply tank. The entire system is connected with the help of thermal resistant pipes and insulated with glass wool. The outlet from the tank is connected to the HTF tube which is made up of copper. Valves are provided in appropriate places to allow the passage of hot water where and when required. The HTF tube is kept inside the TES by keeping the inlet and outlet on the top side of the storage system to avoid the leakage of molten PCM. Polycarbonate tube is selected for thermal energy storage container due to its transparent nature and low thermal conductivity values.

Uniform fins of $10 \mathrm{~mm}$ height are arranged at regular intervals on the copper tube inside the polycarbonate casing. Three fins are attached to the copper tube from the top to the midpoint of the vertical HTF tube. The wall thickness of HTF tube is $1.1 \mathrm{~mm}$ copper tube selection is based on the brazing of copper fins on the outer surface of the HTF tube. The fins are of $0.5 \mathrm{~mm}$ thickness and made up of copper. The fins are longitudinally fitted in such a way that the height of the fins at the bottom is more, the same fin but of lesser height is provided at the midpoint of the central HTF tube. The height of the fin at the bottom is $20 \mathrm{~mm}$ and the height is reduced gradually up to the HTF tube height of $150 \mathrm{~mm}$. The top half of the central HTF tube is provided with uniform length fins, whereas the bottom half is provided with four gradually decreasing length fins of the same material and thickness. 
Table 1

Specifications of the thermal energy storage experimental setup

\begin{tabular}{ll}
\hline \multicolumn{1}{c}{ Item } & \multicolumn{1}{c}{ Values } \\
\hline Heating coil capacity $(\mathrm{kW})$ & $6 \mathrm{~kW}$ \\
Power of the pump $(\mathrm{kW})$ & $0.186 \mathrm{~kW}$ \\
Diameter of the PCM container $(\mathrm{mm})$ & $110 \mathrm{~mm}$ \\
Height of the PCM container $(\mathrm{mm})$ & $310 \mathrm{~mm}$ \\
Material of PCM container & Polycarbonate \\
Wall thickness of polycarbonate & $10 \mathrm{~mm}$ \\
Thermal conductivity of polycarbonate & $0.22 \mathrm{~W} / \mathrm{m} \mathrm{K}$ \\
Light transmissibility & $90 \%$ \\
Deflection temperature of the PCM container & $138^{\circ} \mathrm{C}$ \\
material & $399 \mathrm{~W} / \mathrm{m} \mathrm{K}$ \\
Thermal conductivity of HTF tube & $12.70 \mathrm{~mm}$ \\
Outer diameter of the HTF tube & $11.5 \mathrm{~mm}$ \\
Inner diameter of the HTF tube & $1.01 \mathrm{~mm}$ \\
Thickness of the HTF tube & $90 \mathrm{~mm}$ \\
Outer diameter of HTF coil & $300 \mathrm{~mm}$ \\
Height of the HTF coil & $295 \mathrm{~mm}$ \\
Length of the HTF tube with fins & 8 \\
Number of turns in the HTF coil & $0.5 \mathrm{~mm}$ \\
Thickness of fins & $10 \mathrm{~mm}$ \\
Rength of uniform fins & $2-20 \mathrm{~mm}$ \\
Insulation material & $\mathrm{Glass} \mathrm{wool}$ \\
Thickness of insulation & $30 \mathrm{~mm}$ \\
\hline
\end{tabular}

The HTF tube with uniform and variable length fins is illustrated in Fig.1. The schematic layout of the thermal energy storage experimental setup is shown in Fig. 2. The fin length to thickness ratio for uniform fins is 20 . The fin length to thickness ratio of variable length fins varies gradually from 40 to 4 from the bottom to top.

\subsection{Experimental procedure}

Water is filled in both the supply tank and the reservoir to the required level. The mass of water used in the experiments is $50 \mathrm{~kg}$. It is usually filled up to the bottom level of the pipe outlet of the tank. PT 100 thermocouples are connected to the data logging system to record the temperature of the HTF and different heights of PCM over the stipulated time intervals. The temperature in the tank is allowed to reach $70^{\circ} \mathrm{C}$ with the help of the heaters and thermostat controls. The hot water from the tank is allowed to bypass to the reservoir through a pipe connecting the tank directly to the reservoir. The pump is used to circulate water through the storage. The flow rate is regulated using flow meter and valves at a fixed flow rate of $0.02 \mathrm{~kg} / \mathrm{s}$.

The hot water at a nearly constant temperature of $70^{\circ} \mathrm{C}$ is allowed to flow through the HTF tubes immersed in paraffin wax of melting temperature of $60^{\circ} \mathrm{C}$. Table 2 shows the properties of the PCM. The temperature of the PCM is recorded at intervals of $5 \mathrm{~min}$. The height of the molten paraffin wax increases over time. The charging process is continued until the entire paraffin wax changes from solid to liquid.

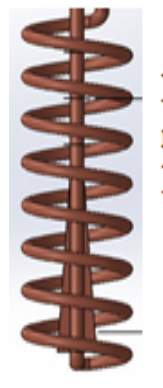

Fins with uniform height of 10 $\mathrm{mm}$ from the periphery of the HTF tube

Fins with variable length from bottom to top (20 mm to $2 \mathrm{~mm}$ )

Fig. 1. Uniform and variable length fins in the concentric HTF tube.

The total time of PCM charging is noted for the HTF tube with and without fins. The tests are repeated four times for both the HTF configurations of with and without fins to check the repeatability. In this analysis, the charging of PCM alone is considered for the HTF with and without fins, as the primary objective is to store maximum heat energy with a short duration.

\subsection{Performance calculations}

The performance is studying by using heat input and storage capacity of the PCM. The heat input to the PCM is calculated using fluid temperatures by Eq. (1).

$$
Q_{i}=\dot{m} C_{p w}\left(T_{w o}-T_{w i}\right) t
$$

Where, $C_{p w}$ - specific heat $(\mathrm{kJ} / \mathrm{kgK}), \dot{m}$ - flow rate $(\mathrm{kg} / \mathrm{s})$, ttime (s), and $T_{w i}, T_{w o}$ - HTF inlet and exit temperatures $\left({ }^{\circ} \mathrm{C}\right)$, respectively. The heat stored by the PCM is calculated by the heat stored by sensible and latent heat using Eq. (2)

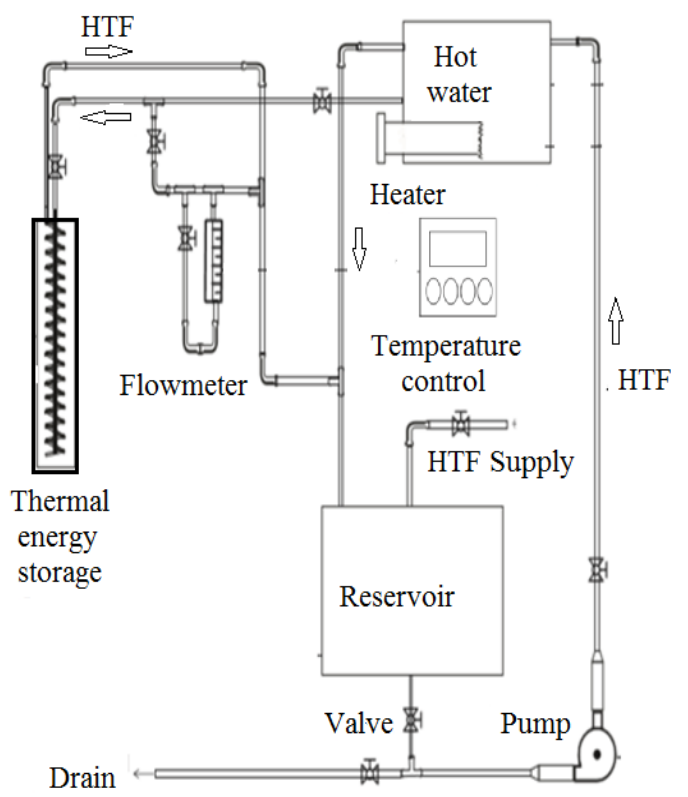

Fig. 2. Schematic layout of the thermal energy storage setup 
Citation: Senthil, R. (2020) Melting Behavior of Phase Change Material in a Solar Vertical Thermal Energy Storage System with Variable Length Fins added on the Heat Transfer Tube Surfaces. Int. Journal of Renewable Energy Development, 9(3), 361-367, doi: 10.14710/ijred.2020.29879

$\mathrm{P}$ a g e 1364

Table 2

Properties of paraffin wax (RT60)

\begin{tabular}{ll}
\hline Property & Values \\
\hline Range of melting temperature $\left({ }^{\circ} \mathrm{C}\right)$ & $58-60$ \\
Phase change enthalpy $(\mathrm{kJ} / \mathrm{kg})$ & 195 \\
Density $\left(\mathrm{kg} / \mathrm{m}^{3}\right)$ & 874 (solid), \\
& 786 (liquid) \\
Thermal conductivity $(\mathrm{W} / \mathrm{m} \mathrm{K})$ & 0.24 (solid), \\
& 0.21 (liquid) \\
Specific heat $(\mathrm{kJ} / \mathrm{kg} \mathrm{K})$ & 2.4 (solid), \\
& 2.2 (liquid) \\
Volumetric expansion $(\%)$ & 10 \\
Mass of PCM used $(\mathrm{kg})$ & 3 \\
Maximum operating temperature $\left({ }^{\circ} \mathrm{C}\right)$ & 130 \\
Flash point $\left({ }^{\circ} \mathrm{C}\right)$ & 210 \\
& \\
Fire point $\left({ }^{\circ} \mathrm{C}\right)$ & 230 \\
\hline
\end{tabular}

$Q=m \cdot\left[C p_{\text {sol }} \cdot\left(T_{m}-T_{i}\right)+H+C p_{\text {liq }} \cdot\left(T_{f}-T_{m}\right)\right]$

Where, $T_{i}, T_{m}$ and $T_{f}$ - initial, melting and final temperatures of PCM $\left({ }^{\circ} \mathrm{C}\right)$, respectively, m - mass of PCM $(\mathrm{kg}), H$ - Latent heat of PCM $(\mathrm{kJ} / \mathrm{kg})$ and $C_{\text {sol, }}, C_{\text {liq, }}$ - specific heat of solid and liquid PCM (kJ/kgK), respectively. The thermal energy storage effectiveness is calculated based on the PCM and HTFs temperature using Eq. (3).

$$
\epsilon=\frac{\left(T_{w i}-T_{w o}\right)}{\left(T_{w i}-T_{m}\right)}
$$

\subsection{Uncertainty analysis}

To validate the experimental measurements and the obtained results, an uncertainty analysis is performed (Kline and McClintock, 1953; Moffat, 1988). Table 3 shows the uncertainties in the measurement of various parameters, namely, mass, temperature, and flow rate.

The overall uncertainty of the experiment is found from Eq. (4),

$\Delta \mathrm{Y}=\sqrt{\sum\left(\frac{\delta Y}{\delta X_{i}} \Delta X_{i}\right)^{2}}$

Where $\Delta \mathrm{Y}$ is the overall uncertainty of the experiment, $\delta \mathrm{Xi}$ and $\delta \mathrm{Yi}$ are the uncertainties in the measured and derived quantities, respectively and $\mathrm{Xi}$ the measured quantity. The experimental uncertainty for storage effectiveness is determined as $3.7 \%$ at the selected mass flow rate. The overall uncertainty decreases as the flow rate increases. A similar effect is also observed in literature (Mehta et al., 2019). Thus, the results of the present work are on par with the research findings in literature.
Table 3

Uncertainties in the measurement of parameters

\begin{tabular}{cc}
\hline Property & Uncertainty \\
\hline Temperature (PT100 sensors) & $\pm 0.1^{\circ} \mathrm{C}$ \\
Mass of PCM (Digital balance) & $\pm 0.01 \mathrm{~g}$ \\
Mass flow rate (Digital flow meter) & $\pm 0.02 \mathrm{~kg} / \mathrm{min}$ \\
Time (Digital stopwatch) & $\pm 0.1 \mathrm{~s}$ \\
\hline
\end{tabular}

\section{Results and discussion}

\subsection{Melting durations}

The parafin wax around the central copper tube and the helical coil starts melting due to the flow of hot water at $70^{\circ} \mathrm{C}$ through the copper tube. The inlet temperature and flow rate of HTF are maintained the same for both the HTF tube configurations of with and without fins. The temperature trend of the PCM at three equal positions in the vertical storage is shown in Fig. 3.

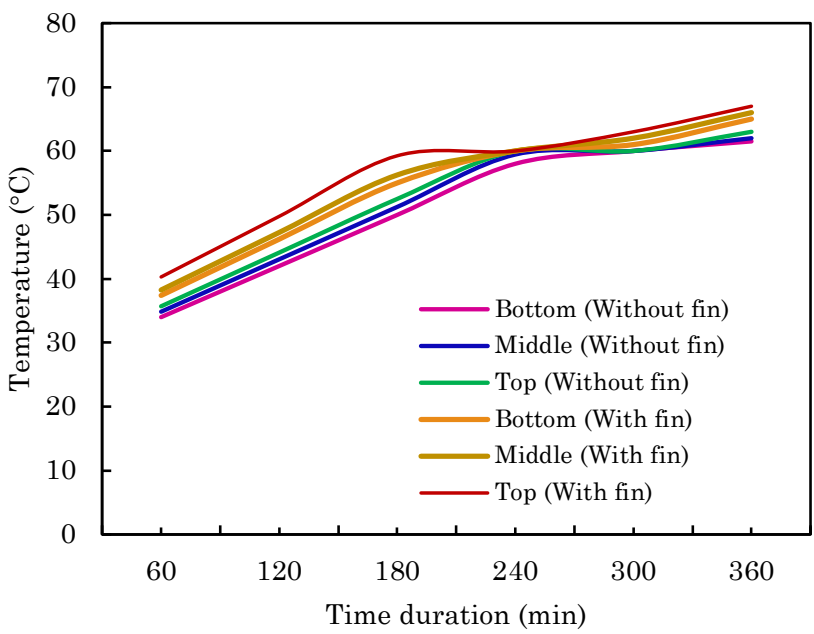

Fig. 3. Variation of PCM temperature (top, middle and bottom) over the test duration for with and without fins in the center HTF tube

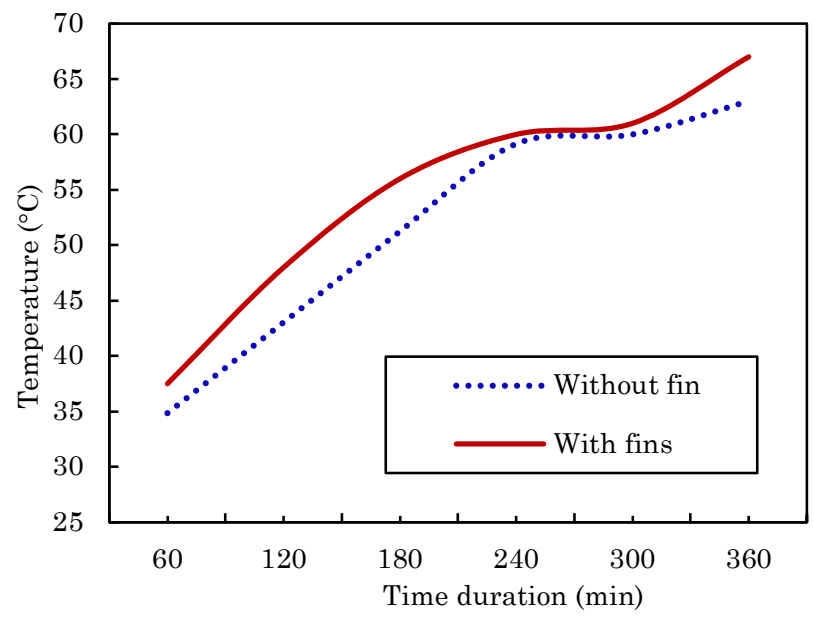

Fig. 4. Variation of average temperature of PCM temperature over the test duration for with and without fins in the center HTF tube for a fixed flow rate and initial HTF temperature 
The fins are found to be beneficial due to the additional heat transfer area and the contact with the PCM, and the temperature trend is at a faster rate when compared to the HTF tube without fins. Sensible heating of PCM with fins occurs at a faster rate than the HTF tube without fins. The temperature profile along the axis from bottom to top shows an increasing trend due to the solid PCM at the bottom and the liquid PCM reaches the top of the storage tank. The average temperature of PCM with fins is observed to be around $5.5 \%$ more temperature that that of the PCM storage without fins as per Fig. 4. The HTF leaving the PCM storage is observed to have a temperature drop of around $3-7^{\circ} \mathrm{C}$ due to the temperature difference between the PCM and water over time. The addition of an outer HTF coil in the system helps in increasing the residence time of HTF inside the copper tubes and in exchanging the heat at a faster rate. The temperature drop of the HTF with fins is to be observed about $10 \%$ more than that of the HTF tube without fins on the central HTF tube surface. The trend of temperature drop in HTF across the PCM storage is illustrated in Fig. 5 .

The different stages of the melting of PCM are visually observed by opening the insulation blanket at intervals of $15 \mathrm{~min}$ and the final stage is observed at after an interval of $5 \mathrm{~min}$. The major stages of melting are presented in Fig. 6. Thus, the molten PCM reaches the top of the storage tank due to natural convection and density difference, and an increase in temperature is also observed in the liquid region. The gradual decrease in fin height is to assist the liquid convection from the bottom to the top of the storage unit. After about $4 \mathrm{~h}$, the height of the liquid paraffin wax is observed to be at a maximum and the remaining duration of heating is required to melt the solid PCM settled at the bottom of the storage. The PCM remaining at the bottom part of the storage unit requires more heating time to melt due to the constant heat loss taking place from the thermal storage system. The gradually increasing length of fins helps in increasing the rate of charging of the paraffin wax.

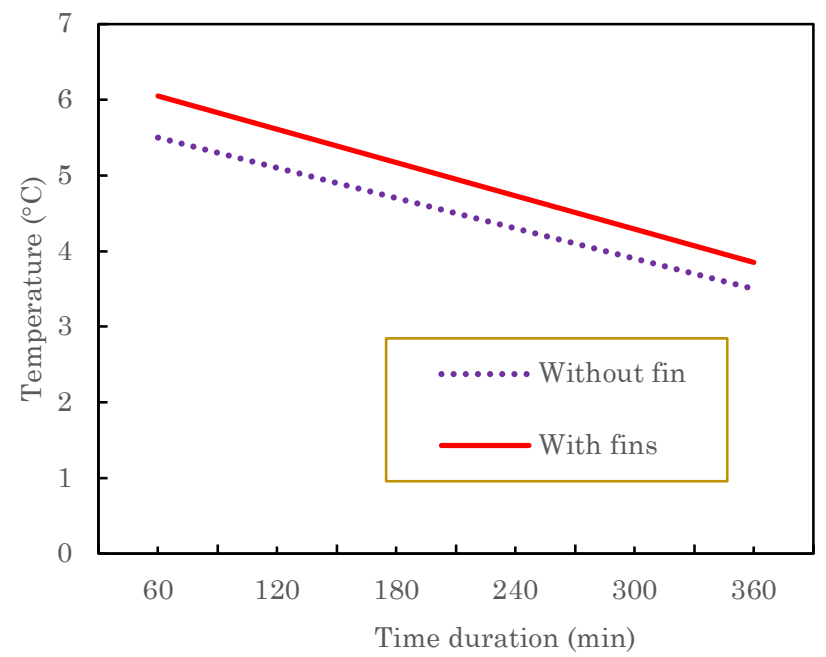

Fig. 5. Temperature drop of HTF across the PCM storage over the test duration for with and without fins in the center HTF tube for a fixed flow rate and initial HTF temperature
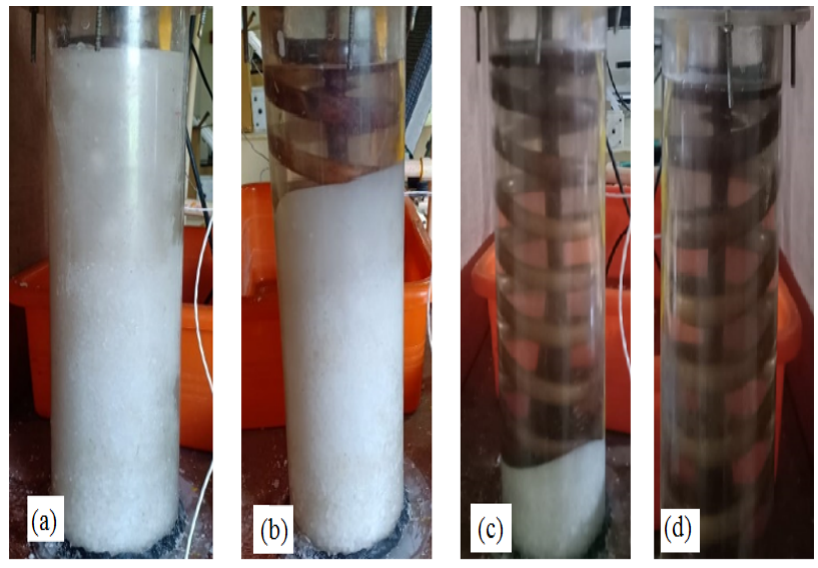

Fig. 6. Melting stages of paraffin wax in vertical PCM storage with helical coil heat transfer fluid tube with uniform and variable length fins; (a) $90 \mathrm{~min}$, (b) $180 \mathrm{~min}$, (c) $270 \mathrm{~min}$, (d) 290 $\min$.

The time taken to reach complete melting is about $340 \mathrm{~min}$ and $300 \mathrm{~min}$, for HTF tube without and with fins, respectively. Thus, the enhancement of melting duration of HTF tube with uniform and variable length fins is about $13.33 \%$ more than that of the HTF tube without fins. Fig. 7 shows the amount of heat stored in the PCM for thermal energy storage for the central HTF tube with and without fins. Thermal energy storage with fins is observed to have about $3.2 \%$ more heat storage capacity than that of thermal energy storage without fins.

\subsection{Storage effectiveness}

The effectiveness of the PCM storage is determined based on the melting temperature of PCM and the HTF inlet and outlet temperatures. The variation of storage effectiveness over the test duration is shown in Fig. 8. The storage effectiveness gradually increases over the test duration when the PCM reaches the melting point. The average storage effectiveness of TES without and with fins is 0.51 and 0.57, respectively. The increase of storage effectiveness of TES with fins is about $11.77 \%$ more than that of the TES without fins.

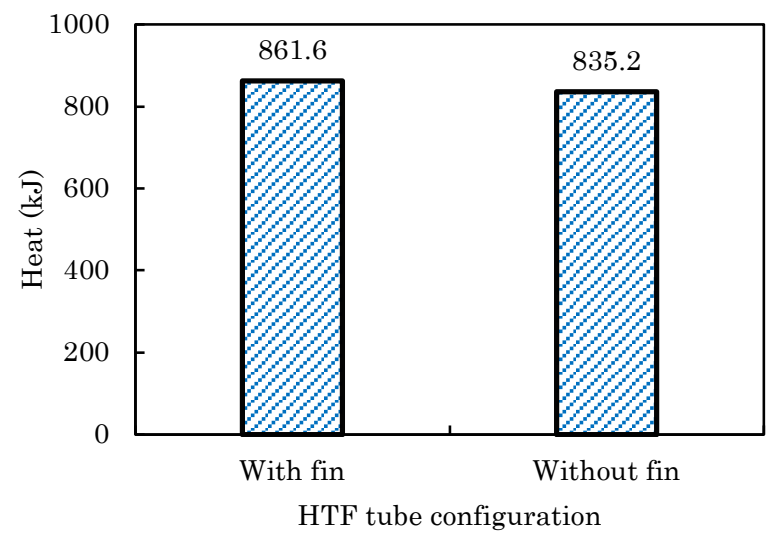

Fig. 7. The amount of heat stored in PCM in both the thermal energy storage for the central HTF tube with and without fins 


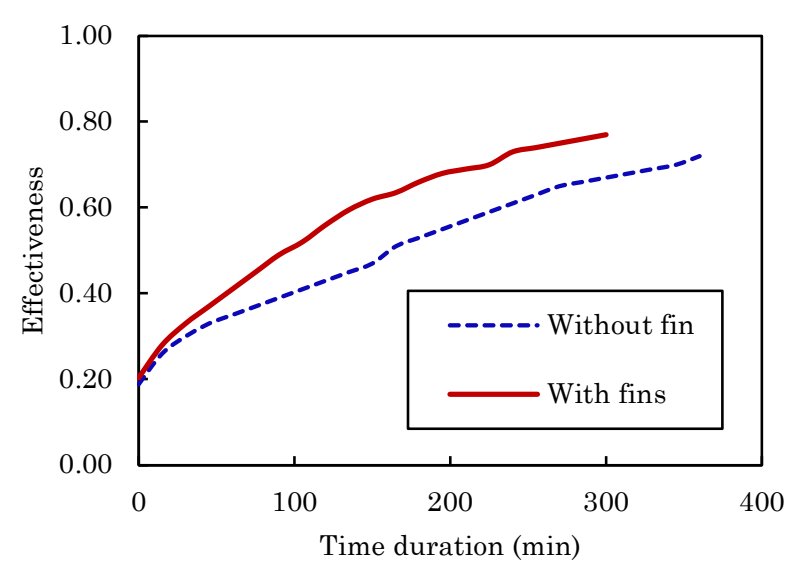

Fig. 8. Variation of the effectiveness of thermal energy storage over the test duration

Fig. 9 shows the comparison of average storage effectiveness and the complete melting time of PCM for the HTF tube with and without fins. A significant variation is observed with the fins regarding the melting duration and storage effectiveness. The uniformly extended fins placed around the tube help in increasing the surface area for heat transfer, and thereby increasing the melting rate of PCM in the system. The thermocline effect exists in the vertical PCM storage.

The use of long fins improves the melting rate of the settled down PCM, consequently increasing the efficiency of the system. The fins also help in increasing the rate of the upward flow of molten PCM. It is observed that the PCM in the top portion of the system melts much faster as compared to the PCM at the lower levels. The higher fin length to thickness ratio is maintained in both the uniform and variable length fins about 20 to improve the natural convection in the molten PCM. The gradually decreasing fin height in the vertical direction assists the movement of liquid PCM to reach the top and provides a dynamic melting phenomenon.

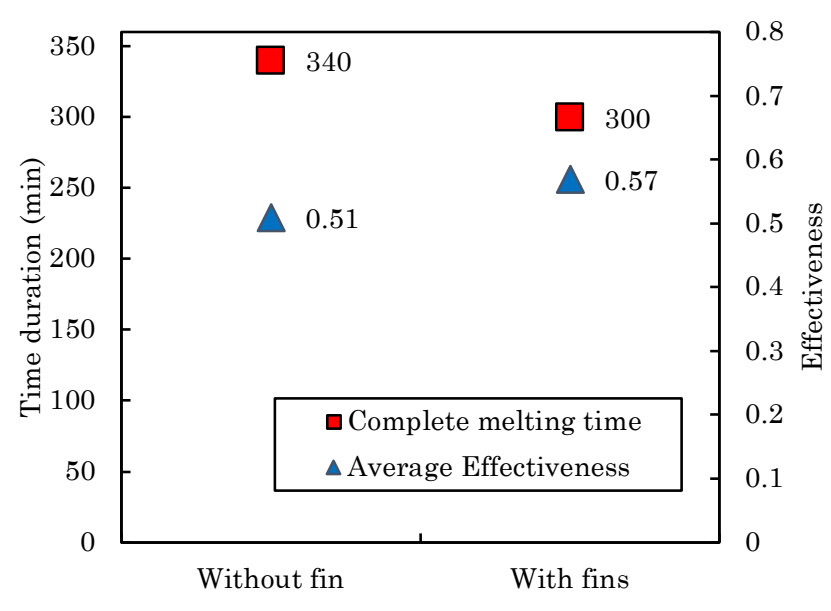

Helical HTF tube configuration

Fig. 9. Time taken to complete the melting of PCM and storage effectiveness of the thermal energy storage for the central HTF tube with and without fins
Thus, the proposed method is helpful in the effective charging of PCM without increasing the complexity of the storage. When compared to other costlier methods like nano-based enhancements, fins are more cost-effective. The construction of fins in the present cylindrical TES system is observed to be effective due to the variable fin length.

\section{Conclusions}

Intermittent solar energy can be effectively utilized using thermal energy storage. Uniform and variable length fins are tested for the melting time using water at a specific temperature of about $70^{\circ} \mathrm{C}$ and a flow rate of $0.02 \mathrm{~kg} / \mathrm{s}$.

- The HTF tube with fins is observed to be effective to completely melt the settled solid PCM in the bottom part of the vertical TES storage container.

- HTF tube with fins is observed to have a $13.33 \%$ faster rate of melting as compared to that of the HTF tube without fins.

- The time required for complete melting of PCM in the HTF tube with fins is observed to be $40 \mathrm{~min}$ less than that of the HTF tube without fins.

- The storage effectiveness increases by $11.77 \%$ with the fins when compared to that of the HTF tube without fins.

- The temperature drop of the HTF across the cylindrical thermal energy storage with fins on the central HTF tube surface is about $10 \%$ more than that of the HTF tube without fins.

- The average temperature of PCM with fins is observed to be around 5.5\% more temperature that that of the PCM storage without fins

- Heat storage capacity of the selected vertical LHS with fins on the central vertical HTF tube is observed to have about $3.2 \%$ more heat storage capacity than that of the thermal energy storage without fins.

The fast charging process helps to increase the rate of heat transfer and to achieve the maximum heat storage in a short period of time. The relationship between the curved profile of fins, storage material, heat transfer mechanisms and the size of the storage container is to be studied further to optimize the design of thermal energy storage.

\section{References}

Aly, K. A., El-Lathy, A. R., \& Fouad, M. A. (2019). Enhancement of solidification rate of latent heat thermal energy storage using corrugated fins. J. Energy Storage, 24, 100785. https://doi.org/10.1016/j.est.2019.100785.

Bhalavi J., Gupta B., Jhinge P.K. \& Pandey M. (2019). Augmenting Distillate Output of Single-Basin Solar Still Using Cement Blocks as Sensible Heat Energy Storage. Advances in Fluid and Thermal Engineering. Lecture Notes in Mechanical Engineering. https://doi.org/10.1007/978-981-136416-7_16.

Chen, C. Q., Diao, Y. H., Zhao, Y. H., Ji, W. H., Wang, Z. Y., \& Liang, L. (2019). Thermal performance of a thermal-storage 
unit by using a multichannel flat tube and rectangular fins. Appl. Energy, 250, 1280-1291. https://doi.org/10.1016/j.apenergy.2019.05.095.

Chen, G., Sun, G., Jiang, D. \& Su, Y. (2020). Experimental and numerical investigation of the latent heat thermal storage unit with PCM packing at the inner side of a tube. Int. J. Heat Mass Transf., 119480 https://doi.org/10.1016/j.ijheatmasstransfer.2020.119480.

Deng, S., Nie, C., Jiang, H., \& Ye, W.-B. (2019). Evaluation and optimization of thermal performance for a finned double tube latent heat thermal energy storage. Int. J. Heat Mass Transf., 130 , $532-544$. https://doi.org/10.1016/i.ijheatmasstransfer.2018.10.126.

Gupta, B., Anil Kumar, \& P.V. Baredar. (2017). Experimental Investigation on Modified Solar Still Using Nanoparticles and Water Sprinkler Attachment, Frontiers in Materials, 4, 23. https://doi.org/10.3389/fmats.2017.00023.

Gürtürk, M., Kok, B. (2020). A new approach in the design of heat transfer fin for melting and solidification of PCM Int. J. Heat Mass Transf., $153,19671$. https://doi.org/10.1016/j.ijheatmasstransfer.2020.119671.

Joybari, M. M., Haghighat, F., Seddegh, S., \& Yuan, Y. (2019). Simultaneous charging and discharging of phase change materials: Development of correlation for liquid fraction. Sol. Energy, 188 ,

788-798. https://doi.org/10.1016/j.solener.2019.06.051.

Khan, L.A., \& Khan, M.M. (2020). Role of orientation of fins in performance enhancement of a latent thermal energy storage unit, Appl. Therm. Eng., 175, 115408. https://doi.org/10.1016/j.applthermaleng.2020.115408.

Kline, S., \& McClintock, F. (1953). Describing Uncertainties in Single-Sample Experiments. Mech. Eng., 75, 3-8.

Kumar, R., \& Verma, P. (2020). An experimental and numerical study on effect of longitudinal finned tube eccentric configuration on melting behaviour of lauric acid in a horizontal tube-in-shell storage unit. J. Energy Storage, 30, 101396. https://doi.org/10.1016/j.est.2020.101396.

Mahdi, M. S., Hasan, A. F., Mahood, H. B., Campbell, A. N., Khadom, A. A., Karim, A. M. A., \& Sharif, A. O. (2019). Numerical study and experimental validation of the effects of orientation and configuration on melting in a latent heat thermal storage unit. J. Energy Storage, 23, 456-468. https://doi.org/10.1016/j.est.2019.04.013.

Mahdi, M. S., Mahood, H. B., Hasan, A. F., Khadom, A. A., \& Campbell, A. N. (2019). Numerical Study on the Effect of the Location of the Phase Change Material in a Concentric Double Pipe Latent Heat Thermal Energy Storage Unit. Thermal Science and Engineering Progress, https://doi.org/10.1016/j.tsep.2019.03.007.

Mahood, H.B., Mahdi, M.S., Monjezi, A.A., Khadom, A.A., \& Campbell, A.N. (2020). Numerical investigation on the effect of fin design on the melting of phase change material in a horizontal shell and tube thermal energy storage, J. Energy Storage, 29. https://doi.org/10.1016/j.est.2020.101331.

Mehta, D. S., Solanki, K., Rathod, M. K., \& Banerjee, J. (2019). Thermal performance of shell and tube latent heat storage unit: Comparative assessment of horizontal and vertical orientation. J. Energy Storage, 23, 344-362. https://doi.org/10.1016/j.est.2019.03.007.

Moffat, R.J. (1988). Describing the Uncertainties in Experimental Results. Exp. Therm. Fluid Sci., 1, pp. 3-17.

Mostafavi, A., Parhizi, M., Jain, A. (2020). Semi-analytical thermal modeling of transverse and longitudinal fins in a cylindrical phase change energy storage system, International Journal of Thermal Sciences, 153,106352. https://doi.org/10.1016/j.ijthermalsci.2020.106352.

Senthil, R. (2019). Effect of position of heat transfer fluid tube on melting of phase change material in cylindrical thermal energy storage. Energy Sources Part A., https://doi.org/10.1080/15567036.2019.1649751.

Senthil, R. (2019). Effect of uniform and variable fin height on charging and discharging of PCM in a horizontal cylindrical thermal storage. Therm. Sci., 22, 3B, 1981-1988, 2019. DOI: https://doi.org/10.2298/TSCI170709239S.

Shahsavar, A., Shaham, A., \& Talebizadehsardari, P. (2019). Wavy channels triple-tube LHS unit with sinusoidal variable wavelength in charging/discharging mechanism. Int. Commun. Heat Mass Transf., 107, 93-105. https://doi.org/10.1016/j.icheatmasstransfer.2019.05.012.

Shukla A.P., Gupta B., Kushwaha R. \& Jhinge P.K. (2019). Thermal Performance of Solar Air Heater Having TriangularShaped Hollow Bodies Inside. Advances in Fluid and Thermal Engineering. Lecture Notes in Mechanical Engineering. https://doi.org/10.1007/978-981-13-6416-7_14.

Sodhi, G. S., Jaiswal, A. K., Vigneshwaran, K., \& Muthukumar, P. (2019). Investigation of charging and discharging characteristics of a horizontal conical shell and tube latent thermal energy storage device. Energy Convers. Manage. 188, 381-397. https://doi.org/10.1016/j.enconman.2019.03.022.

Vogel, J., \& Johnson, M. (2019). Natural convection during melting in vertical finned tube latent thermal energy storage systems. Appl. Energy, 246, 38-52. https://doi.org/10.1016/j.apenergy.2019.04.011.

Wang, Y., Yu, K., \& Ling, X. (2019). Experimental and modeling study on thermal performance of hydrated salt latent heat thermal energy storage system. Energy Convers. Manage., 198 ,

111796. https://doi.org/10.1016/j.enconman.2019.111796.

Yadav, A.K., Donepudi, T., Siddani, B.S. (2020). Numerical and experimental investigation of melting characteristics of phase change material-RT58. Therm. Sci. Eng. Prog., 17,100378. https://doi.org/10.1016/j.tsep.2019.100378.

Yagci, O.K., Avci, M., \& Aydin, O. (2019). Melting and solidification of PCM in a tube-in-shell unit: Effect of fin edge lengths' ratio. J. Energy Storage, 24, 100802. https://doi.org/10.1016/j.est.2019.100802.

Yun, B.Y., Park, J.H., Yang, S., Wi, S. \& Kim, S. (2020). Integrated analysis of the energy and economic efficiency of PCM as an indoor decoration element: Application to an apartment building. Solar Energy, 196, 437-447. https://doi.org/10.1016/j.solener.2019.12.006. 